\title{
Humanitas: la persona en el centro del proceso de formación
}

\section{Albert Florensa Giménez'}

Palabras clave: Humanismo, Ratio Studiorum, Peter-Hans Kolvenbach, Diego de Ledesma, Compañía de Jesús, universidad, formación integral de la persona.

Key words: Humanism, Ratio Studiorum, Peter-Hans Kolvenbach, Diego de Ledesma,Jesuits, Society of Jesus, university, education of the whole person.

Uno de los cuatro principios que caracteriza la educación superior de la Compañía de Jesús en el denominado "paradigma Ledesma-Kolvenbach" es la "humanitas", es decir, la dimensión humanista. El P. Peter-Hans Kolvenbach, General de la Compañía de Jesús entre los años 1983 y 2008, sostiene que

la formación universitaria debe contribuir a un crecimiento integral -cuerpo y espíritu, intelectualidad y afectividad- de la persona humana, que es, escribe Diego de Ledesma [1520-1575], el ornato, el esplendor y la perfección de la naturaleza racional y de la naturaleza humana. ${ }^{2}$

En los centros universitarios, antes que futuros científicos o profesionales de uno $u$ otro terreno, formamos personas en toda su integridad. La formación técnica y científica nunca debe ir separada de esta formación integral, clave para entender la pedagogía de los centros superiores de la Compañía de Jesús.

\footnotetext{
${ }^{1}$ Albert Florensa es profesor de la Cátedra de Ética y Pensamiento Cristiano del IQS (Instituto Químico de Sarriá), Universidad Ramón Llull, Barcelona, y miembro del Laboratorio de Análisis y Crítica Social (LACS), del mismo centro.

2 P.-H. KOLVENBACH (2006), 240.
} 
Aquí analizaremos el humanismo a cultivar en las universidades, en el contexto histórico presente, concretamente en el momento actual de adaptación de los planes de estudio al Espacio Europeo de Educación Superior (EEES), también llamado "programa Bolonia". Estructuraremos nuestro estudio en cinco partes. Cada una de ellas se dedicará a una característica significativa de esta dimensión "humanitas". En cada parte, comentaremos algunos fragmentos de las reflexiones de Kolvenbach, ofreceremos ejemplos que concreten aspectos esenciales de la característica presentada, y plantearemos preguntas sobre las implicaciones que la característica en cuestión debería tener en el trabajo docente e investigador de nuestros centros, y en particular a la hora de elaborar nuestras programaciones. Por supuesto, nuestro estudio pretende incitar a la reflexión, y no extender recetas prescriptivas, que, con toda seguridad, se adaptarían mal a las realidades plurales de nuestros centros.

Partiendo de las reflexiones del P. Kolvenbach, estas son las cinco características significativas del humanismo ("humanitas") que vamos a estudiar aquí: es un humanismo 1/ "desde la fe encarnada", 2/ "que valora la razón", 3/ "comprometido con todos los hombres", 4/ "que conlleva una formación integral de la persona", y $5 /$ "que promueve la libertad y la justicia".

\section{Un humanismo desde la fe encarnada}

No pretendemos aquí bucear en la dimensión "fides" del paradigma LedesmaKolvenbach, que ya tiene sus capítulos propios en esta misma publicación. Simplemente deseamos mostrar el terreno en el que se asienta la "humanitas" presentada por Kolvenbach. Si "humanitas" es una de las aspas de la hélice que ha de dinamizar la vida de un centro universitario de la Compañía de Jesús, entonces el motor que mueve la hélice no es otro que una concepción cristiana del hombre, más concretamente, una antropología conformada a través de la espiritualidad de San Ignacio de Loyola.

Las raíces cristianas del modelo que nos presenta Kolvenbach, en vez de delimitar o excluir a aquellos que no participan de la creencia cristiana, reconocen la totalidad de la naturaleza humana y la totalidad de los hombres. Lejos de representar una dificultad insalvable, como ha ocurrido en otras formulaciones de humanismos cristianos, las raíces cristianas de la "humanitas" de Kolvenbach impulsan, tal como hemos dicho, la apertura a todas las dimensiones del hombre y la apertura a todos los hombres. La razón de esta vocación por lo humano se encuentra en la 
convicción de que la fe en Dios y la afirmación de todo lo que es verdaderamente humano son inseparables entre sí. ${ }^{3}$

Sin ocultar el origen de la energía que dinamiza nuestros centros, ha de quedar claro cuál es el "principio general que ha regido la enseñanza y la acción de los jesuitas desde la fundación de la Orden: saber promocionar la eminente dignidad de la persona humana a través, y más allá, de sus adhesiones personales (étnicas, lingüísticas, religiosas). (...) Un sociólogo contemporáneo [definía] en estos términos el lema de los jesuitas: para ellos, dice, 'no hay nada que separe profundamente al hombre del cristiano; el segundo es la perfección del primero'. ¿Puede ser de otro modo para el que cree que el Verbo ha levantado su tienda entre nosotros?" 4

Por otra parte, la Congregación General 35 de la Compañía de Jesús deja muy clara la vocación de apertura y de colaboración con todos los hombres:

debemos trabajar con los demás: religiosos y religiosas de otras comunidades, laicos, miembros de movimientos eclesiales, personas que comparten nuestros valores pero no nuestras creencias, en una palabra, todas las personas de buena voluntad. ${ }^{5}$

El humanismo que se deriva de este principio también contempla y promueve necesariamente las diferentes dimensiones de las actividades humanas. Desde el más humilde trabajo hasta aquellas acciones basadas en el desarrollo de lo científico-racional, lo artístico y lo espiritual trascendente.

Por otra parte, el mensaje "dominad la tierra" $(G e n 1,28)$ es una exhortación a que el hombre se responsabilice de humanizar la tierra. El hombre ha sido creado creador, y debe asumir la tarea productiva sin olvidar la necesaria comunión con la Creación, respetando los ritmos naturales y evitando la expoliación, y sin olvidar tampoco el hecho de que

la preeminencia del hombre en la Creación no sería tal si no lo fuese de todos los hombres. Si lo fuese sólo de unos pocos, entonces no lo sería en virtud de su condición de hombres, sino en razón de alguna otra particularidad (racial, religiosa o de algún otro tipo). Por tanto, la particular dignidad del hombre es la que funda la unidad de todo el género humano, más allá de tantas diferencias experimentables e insuperables: judíos y

3 P.-H. KOLVENBACH (1993), 126.

4 P.-H. KOLVENBACH (2000), 156-157.

${ }^{5}$ CG35, 2, 21 
pueblos no elegidos, opresores y oprimidos, gentes que viven en el Neolítico y que son contemporáneos de otros que viven en el siglo XXI. ${ }^{6}$

Hoy, si cabe, más que en otros tiempos -por el papel que representa el conocimiento-, la responsabilidad de las universidades resulta decisiva en esa comunión creadora.

Por ello, debemos plantearnos hacia dónde apuntan los intereses y los esfuerzos de nuestras universidades, para ver si contribuyen o no a la construcción de un mundo realmente humano, y por tanto plural.

En otras palabras, el humanismo cristiano de finales de siglo XX incluye necesariamente el humanismo social. Como tal, participa en gran parte de los ideales de otras creencias, al pretender que el amor de Dios se manifieste eficazmente, y que se edifique un Reino de Dios justo y pacífico en la tierra (...). Esto requiere creatividad en todos los campos del pensamiento, educación y espiritualidad?

La "humanitas" de Kolvenbach no se limita a una simple abstracción de lo humano, sino que también contempla al ser humano concreto. En particular, al referirse a los alumnos de nuestros centros, afirma que

estos jóvenes necesitan confianza para mirar al porvenir; necesitan fuerza para afrontar su propia debilidad; necesitan la comprensión y afecto maduros de los profesores de todas las asignaturas, con los que pueden explorar el asombroso misterio de la vida. (...) Ayudadles a reconocer que son dignos de respeto y aprecio. ${ }^{8}$

Tal visión conduce necesariamente a plantearnos varios interrogantes. ¿¿De qué modo tenemos en cuenta a los alumnos en nuestros planes de estudio?

Aun conociendo las limitaciones de diferente naturaleza a las que está sometida la elaboración de planes de estudio, el alumno debería ser uno de los centros de atención en esta tarea, no implicándole en la elaboración del nuevo plan (quizás sí podrían participar algunos ex-alumnos), sino sabiendo que su formación es el objetivo último. Sin olvidar las limitaciones propias de cualquier institución, y sin olvidar tampoco los bienes extrínsecos de cualquier actividad humana-como, por ejemplo, el prestigio social de una universidad-, nuestros centros deberían ser

\footnotetext{
6J. I. González Faus (1987), 77.

7 P.-H. KOLVENBACH (1993), 127.

8 lbid., 129-130.
} 
excelentes en la formación de futuros profesionales. ¿Desarrollamos la actividad cooperativa entre nuestros estudiantes?

No cabe duda de que muchos de nuestros centros gozan de un gran prestigio social, pero no es menos cierto que algunos de ellos han sido tildados de "elitistas" por haber fomentado una malsana competitividad entre sus alumnos. Sin renunciar a la exigencia, los resultados académicos individuales de cada alumno no deberían ser el único dato que sirviese para evaluar el progreso de los estudiantes. Hay que fomentar también el trabajo en equipo, la cooperación, la dimensión social, y solidaria, de la persona.

Si la atención a aquellos alumnos que siguen con éxito sus estudios en nuestras aulas es algo importante, el seguimiento de los alumnos con problemas, para poder orientarlos a encontrar su vocación, es algo esencial. Entre los alumnos que nos han de dejar por no haber podido superar sus estudios, algunos lo hacen con la sensación de haber vivido una experiencia destructora. No debería ser así.

Sin embargo, ninguna de las preguntas anteriores cuestiona la importancia del "magis" ignaciano. La responsabilidad que cada hombre tiene con respecto a los talentos que ha recibido (Mt 25,14-30) debe ser proclamada y exigida en nuestros centros. Esa exigencia resulta clave, no sólo para la obtención de resultados excelentes en el proceso de aprendizaje e investigación, sino también en la educación de la voluntad en la praxis ética. Que la voluntad no esté considerada en nuestros objetivos formativos condena a cualquier asignatura relacionada con la ética a la ineficacia.

Las palabras del jesuita Aimé Duval, el famoso cantautor Lucien, en referencia a los tres amores que él considera inherentes al ser humano, y que describe en el libro donde relata sus vivencias como alcohólico y su lucha por liberarse de esta adicción, constituyen una interesante síntesis experiencial de lo dicho hasta aquí sobre esta fe encarnada que acompaña, como el bajo continuo en la música barroca, a la "humanitas" de Kolvenbach, un acompañamiento que debería sonar nítidamente en nuestros centros:

Hoy pienso que estos tres amores (a Dios, a los demás y a mí mismo) deberían tener la misma intensidad.

Amar a Dios sin amar a los demás es beatería.

Amar a los demás sin amar a Dios (conociendo a éste) es falta de lógica de espíritu.

Amarse a sí mismo sin amar a los demás da lugar a un mundo (...) en el que la violencia acabará estrangulando a los que sobrevivan.

Amar a los demás sin amarse a sí mismo es una enfermedad que puede conducir al alcohol. 
Ahora, sobrio desde hace catorce años, sé que mi felicidad depende del equilibrio entre estos tres amores. ${ }^{9}$

\section{Un humanismo que valora la razón}

No cabe duda alguna del lugar privilegiado que Ignacio de Loyola concede a la razón. Así, por ejemplo, en sus Ejercicios Espirituales afirma que

después que así he discurrido y raciocinado a todas partes sobre la cosa propósita, mirar dónde más la razón se inclina, y así, según la mayor moción racional, y no moción alguna sensual, se debe hacer deliberación sobre la cosa propósita. ${ }^{10}$

Kolvenbach sostiene que

Ignacio se muestra convencido de la importancia del trabajo de la inteligencia, que consiste en realizar plenamente lo que el Creador ha querido para el hombre, dotándole de una inteligencia capaz de conocer lo verdadero y lo falso, el bien y el mal, la tierra y el cielo. De esta creencia Ignacio extrae un intelectualismo optimista. En su tiempo, que, como en el nuestro, reinaba una gran confusión de ideas -el re-nacimiento, la re-forma-cree profundamente en este don de Dios que es la inteligencia informada de la verdad total y en una voluntad eliminada por la recta razón. ${ }^{11}$

Es obvio que en el terreno de la inteligencia y de la razón, la universidad juega un papel clave. Lo jugó en tiempos de lgnacio y lo sigue haciendo en la actualidad. Si bien algunas de las estrategias que desarrollan y conforman la inteligencia humana siguen siendo las mismas que preocuparon a lgnacio y a los suyos, nuestra realidad, caracterizada por la globalización e inervada por las tecnologías de la información y de la comunicación, exige la exploración de nuevas vías ante desafíos nunca antes planteados a la humanidad.

Así pues, no debemos olvidar la riqueza de la tradición educativa y pedagógica ignaciana tal como se recoge en la "Ratio Studiorum" y en las sucesivas actualizaciones y adaptaciones que se han hecho de este programa, en particular, las desarrolladas por estudiosos dedicados a las enseñanzas secundarias. No ha

\footnotetext{
${ }^{9}$ A. DUVAL (1997), 148.

10 IGNACIO de Loyola, Ejercicios Espirituales, n. 182, cit. en: P.-H. KolvenBACH (2006), 239.

${ }^{11}$ P.-H. KolvenBACH (2006), 239.
} 
resultado difícil, por ejemplo, descubrir en las propuestas pedagógicas y didácticas de la "Ratio Studiorum" estructuras análogas a la del aprendizaje significativo que, hace relativamente poco tiempo, nos eran presentadas como buenas alternativas a la enseñanza basada en la memorización mecánica.

La elaboración de pensamiento propio y la consideración de la razón a la hora de tomar decisiones han de ser capacidades que estén presentes en los programas y en las metodologías practicadas en nuestros centros. Para ello, deberemos favorecer el papel orientador y dinamizador de los profesores en el proceso de aprendizaje de sus alumnos, evitando que los docentes se conviertan en meros transmisores de una información que posteriormente los alumnos deberán repetir en los exámenes. Sólo desde el propio aprendizaje, orientado como hemos dicho por los profesores, conseguiremos la autonomía intelectual de los alumnos. La ejercitación mediante casos que obliguen a los alumnos a tener que tomar decisiones racionales puede resultar un método eficaz para desarrollar esa autonomía. En este sentido, deberíamos cuestionarnos por el tipo de aprendizaje que llevamos a cabo en nuestras instituciones y el papel que en él representan alumnos y profesores.

Todo lo dicho hasta aquí debe situarse en el contexto creado por el crecimiento exponencial de la información que se ha dado estos últimos años. Citemos dos ejemplos de ese crecimiento propio de la llamada "sociedad de la información": $1 /$ durante los últimos 30 años se ha producido más información en el mundo que en los anteriores 5.000 años; un ejemplar de la edición dominical de The New York Times contiene más datos que los que habría sido capaz de digerir una persona culta del siglo XVIII durante toda su vida; ${ }^{12}$ y 2 / en 1870 , se publicaron en el mundo unos 840 artículos sobre matemáticas, mientras que sólo en 1994 se publicaron $50.000 .{ }^{13}$

Como en cualquier otra aportación de la técnica, dado el carácter ambivalente de ésta, frente a las indudables ventajas que nos ofrece ese extraordinario caudal de información al que hacíamos referencia, aparecen también efectos negativos. Destaquemos dos de estos efectos: 1/ el exceso de información nos obliga a desarrollar la capacidad de protegernos de él y de filtrar la información para que ésta nos pueda ser de utilidad o, si se prefiere, para que pueda convertirse en conocimiento; el sociólogo Zygmunt Bauman define este reto con las siguientes palabras

12 I. RAMONet (1999), La Tyrannie de la communication, Galilée, París, cit. en: Z. BAUmAN (2007), 21.

${ }^{13}$ A. M. Odyzco (1995), "Tragic loss or good riddance? The impending demise of traditional scholarly journals", Notices of the American Mathematical Society (enero), cit. en: H. F. Judson (2006), 368. 
de Thomas H. Eriksen: Por todas partes hay demasiada información. Una habilidad decisiva en la sociedad de la información consiste en protegerse del 99,99\% de los datos que no te interesan; ${ }^{14}$ y Bauman comenta: Podríamos decir que la línea que separa el mensaje válido (el objeto aparente de la comunicación) del ruido de fondo (su adversario y obstáculo reconocidos) ha desaparecido del todo. ${ }^{15}$

Planteamos dos preguntas:

- ¿Proporcionamos métodos y criterios para buscar y seleccionar información?

- ¿QQué papel tienen en nuestros planes de estudio la formación del análisis, de la crítica y de la síntesis de la información?

Los problemas generados por esta exuberancia informativa no son únicamente de orden cuantitativo. El escollo no se reduce a un filtraje complicado por causa del enorme volumen de información que nos llega, sino que las dificultades también se dan a la hora de elaborar un pensamiento que sea amplio y consistente.

Cuando una cantidad creciente de datos se distribuye también a una velocidad creciente, cada vez resulta más difícil crear narraciones, conjuntos, secuencias con un desarrollo concreto. Los fragmentos corren el peligro de convertirse en hegemónicos. Este fenómeno tiene una influencia directa sobre nuestra manera de relacionarnos con el saber, el trabajo y la vida en general. ${ }^{16}$

$\mathrm{Si}$, tal como veremos más adelante, actualmente, la hiperespecialización parece ser una exigencia en la formación superior, más aún en la investigación, este tipo de fragmentación al que nos referíamos parece ir a favor de tal exigencia. Por tanto, el riesgo de elaborar pensamiento fragmentado será muy grande: para los que elaboran este tipo de pensamiento resulta difícil construir discursos de sentido que contemplen la realidad humana considerada en su totalidad con la finalidad de ofrecer criterios de valoración. Lo exclusivamente fragmentario, opuesto a lo holístico, diluye la vida y la existencia haciendo prácticamente imposible la valoración de éstas, puesto que no considerarlas holísticamente las priva de su auténtica realidad. Como sostiene la Gestalt, "el todo es más que la suma de sus partes". De hecho,

14 Z. BAUMAN (2007), 21.

$15 \mathrm{lbid}$.

${ }^{16}$ T. H. ERIKSEN, Tyranny of the Moment: Fast and Slow Time in the Information Age, Sterling: Pluto Press, 2001, cit. en: Z. BAUMAN (2007), 23-24. 
Bauman, tomando expresiones de Georg Simmel, advierte que la fragmentación conduce a mostrar 'una actitud indiferente' hacia 'el saber, el trabajo y la vida' (en realidad, hacia la vida como tal y hacia todo lo que contiene). ${ }^{17}$ Simmel decía que a la persona indiferente, las cosas se le muestran bajo un color uniformemente apagado y grisáceo; ningún objeto merece distinguirse de los demás. ${ }^{18}$

\section{Un humanismo comprometido con todos los hombres}

Ya hemos recordado más arriba que, para Kolvenbach, el principio por el que se ha guiado siempre la enseñanza y la acción de los jesuitas no ha sido otro que saber promocionar la eminente dignidad de la persona humana a través, y más allá, de sus adhesiones personales (étnicas, lingüisticas, religiosas). ${ }^{19}$ Él insiste en la actitud abierta que debería recorrer nuestros centros al afirmar que es bueno mantenerse fiel

a esta tradición, a la vez humanística y auténticamente cristiana, inherente a la espiritualidad de la Compañía de Jesús, a este espíritu de apertura incondicional a los hombres y mujeres de todo origen y de toda comunidad en nombre de su humanidad común, a este ideal de servicio al otro en tanto que es el otro, cualesquiera que sean sus pertenencias sociales y culturales. ${ }^{20}$

¿Facilitan nuestros centros el marco teórico para el descubrimiento del otro?

Sin conciencia de alteridad se hace imposible cualquier reflexión ética. La filosofía moderna occidental reivindicó el yo, formuló la inviolabilidad de la dignidad humana y denunció todas las cadenas que impedían al ser humano alcanzar su mayoría de edad en forma de autonomía. Magnos logros a los que, sin duda alguna, no podemos ni debemos renunciar. De hecho, la crítica de los totalitarismos y la defensa de las libertades han ocupado una buena parte de la historia del siglo XX y, en la actualidad, siguen siendo protagonistas de la dinámica humana. Sin embargo, una interpretación ensimismada del yo conduce necesariamente a un yo inválido para la ética. Clara Gomis nos recuerda que Emmanuel Lévinas

\footnotetext{
17 Z. BAUMAN (2007), 24.

${ }^{18}$ G. Simmel, Die Grossstäde und das Geistesleben, cit. en: Z. Bauman (2007), 24.

19 P.-H. KolvenBACH (2000), 156.

$20 \mathrm{lbid} ., 157$.
} 
advierte de este peligro. Para Lévinas, escribe Gomis, el otro es aquel capaz de afectarme y despertar mi conciencia; el yo es aquel capaz de escuchar al otro y responder a sus necesidades. Lo esencialmente humano es, pues, la relación ética: salir de uno mismo, ceder al otro el primer lugar. ${ }^{21}$ Más aún, el origen de la ética es el encuentro con el otro: su rostro, su piel desnuda y en especial sus ojos sacuden nuestro ser cómodamente instalado en la mismidad, ocupado en afirmarse y preocupado por su propia muerte. ${ }^{22}$

Debemos preguntarnos por el ambiente y por el tipo de relaciones que fomentamos en nuestros centros, en particular, en las aulas y en los departamentos. $\dot{2}$ Propiciamos los espacios concretos y las condiciones prácticas para que pueda darse el encuentro con el otro?

Este "otro" al que nos referimos aquí puede estar próximo o alejado, tanto en el en el tiempo como en el espacio. La tecnociencia ha dotado al hombre de un poder tal que las responsabilidades de éste van más allá de la que pueda tener simplemente con sus conciudadanos más próximos. La filosofía griega, preocupada fundamentalmente por lo reducido de una ciudad, la "polis", no nos da una respuesta completa a los retos planteados por la nueva aldea global, y menos aún dice nada acerca de nuestra responsabilidad en las acciones tecnocientíficas que afectarán a los que aún no existen, las generaciones futuras.

Por otra parte, ese yo narcisista, prepotente y cerrado, denunciado por Lévinas, se halla en el corazón de algunas antropologías que fundamentan planteamientos de la economía tales como las visiones neoliberales contemporáneas al estilo de las de la Escuela de Chicago. Ya en el siglo XIX, John Stuart Mill escribía las siguientes palabras en referencia a tales formas de pensamiento: "Confieso que no me agrada el ideal de vida que defienden aquellos que creen que el estado normal de los seres humanos es una lucha incesante por avanzar; y que el pisotear, empujar, dar codazos y pisarle los talones al que va delante, que son característicos del tipo actual de vida social, constituyen el género de vida más deseable para la especie humana" ${ }^{23} \dot{ }$ Desenmascaramos las antropologías subyacentes a las teorías sociales, normalmente agazapadas tras aparentes fundamentaciones científicas?

${ }^{21}$ C. Gomis (2006), 33-34.

22 Ibid., 33

23 J. S. Mill, Principios de economía política, Ciudad de México, Fondo de Cultura Económica, 1978, 641, cit. en: L. González-Carvajal (1998), 123. 
Si ese yo narcisista, encerrado en sí mismo, ya representa una dificultad para descubrir la alteridad, también la realidad plural que caracteriza nuestras sociedades puede incrementar aún más esa cerrazón. El miedo a lo nuevo, a lo diferente, a los diferentes, puede conducirnos a una sociedad de comunidades aisladas y también de guetos. Si a esto sumamos la añoranza de tiempos pasados en los que parecía existir una única religión, una única moral, en definitiva, una única cosmovisión válida, entonces el peligro de la división y del conflicto social parecen definitivos. Todo esto pensando en nuestra sociedad; pero la cosa aún se complica más si consideramos que nuestro mundo ya constituye una aldea global.

Vivir humanamente en una sociedad, en un mundo plural, en el que existen diferentes maneras de concebir los proyectos de sentido y de felicidad, pasa necesariamente por desarrollar una ética cívica. Las diferentes opciones de sentido de vida humana, de vida feliz, en definitiva, las diferentes éticas de máximos, enraizadas en diferentes concepciones, ya sean religiosas, agnósticas o ateas, necesitan de unos mínimos morales consensuados por todos para poder convivir en plenitud humana desarrollando su proyecto felicitante, esto es, que lleva a la felicidad.

Tal como apunta la filósofa Adela Cortina, los contenidos mínimos de una ética cívica son: a) los valores de libertad, igualdad y solidaridad; b) los derechos humanos; c) la tolerancia activa; $y$ d) un ethos dialógico o actitud de diálogo.

Admitir los valores de libertad, igualdad y solidaridad, así como los derechos humanos, tiene consecuencias directas sobre la forma de presentar las profesiones que aprenderán nuestros alumnos. Así, por ejemplo, será necesario que los futuros empresarios que estamos formando no sitúen el beneficio económico por encima de los derechos humanos, o que los futuros ingenieros los tengan en cuenta a la hora de valorar el impacto de sus acciones tecnocientíficas, aun cuando las leyes de un Estado no reconozcan estos derechos. La formación en ética profesional puede resultar muy valiosa en este sentido.

Más aún, la formación en la tolerancia y en la actitud de diálogo es imprescindible para poder convivir en un contexto plural. Según Adela Cortina, la tolerancia pasiva es entendida sólo como una predisposición a no inmiscuirse en los proyectos ajenos por simple comodidad, pero hay otra tolerancia, en un sentido activo, [entendida] como una predisposición a respetar proyectos ajenos que pueden tener un valor,

J. S. MILL (1978), 641.

Revista de Fomento Social 63 (2008) 
aunque no lo compartamos. La tolerancia pasiva no sirve de base para construir un mundo juntos: para construir hace falta tolerancia activa. ${ }^{24}$

La actitud de diálogo, el ethos dialógico, es el que va a permitir

conjugar dos posiciones éticas, que algunos autores tienen por difíciles de conciliar: el universalismo y el respeto a la diferencia. Creen estos autores que el respeto a la diferencia nos lleva a una situación en que no puede defenderse ningún valor con pretensiones de universalidad, porque entonces ahogaríamos la diferencia. $Y$, sin embargo, es justo lo contrario: sólo si reconocemos que la autonomía de cada hombre tiene que ser universalmente respetada, podremos exigir que se respeten sus peculiaridades, y la forma de hacerlo será a través de diálogos en los que cada quien exprese tales peculiaridades desde la unidad que supone saberse al menos mínimamente entendido y máximamente respetado. ${ }^{25}$

¿Se dan en nuestros centros los medios y los espacios necesarios para fomentar y desarrollar la tolerancia activa y el ethos dialógico?

\section{Un humanismo que conlleva una formación integral de la persona}

Kolvenbach afirma con convicción el carácter interdisciplinar que ha de tener la educación superior en los centros universitarios de los jesuitas. Para él, servir al estudiante es garantizarle una formación integral que le permita actuar con competencia y humanidad en el mundo de mañana. ${ }^{26}$ Insiste en ello cuando, con motivo del centenario del IQS (Instituto Químico de Sarriá), un centro dedicado a la formación y a la investigación científica, técnica superior y económica, afirma que la Misión universitaria del Instituto Químico de Sarriá aspira a enseñar a los estudiantes a desarrollar una reflexión más sintética, más global y a ir adquiriendo una actitud más apta para la reflexión interdisciplinar. ${ }^{27}$

En el pensamiento de Kolvenbach, la interdisciplinariedad no es un impedimento para la calidad en la formación de nuestros estudiantes, ni tampoco un añadido folclórico: "lejos de debilitar o impedir el rigor científico y el nivel de la búsqueda

\footnotetext{
${ }^{24}$ A. CORTINA (1994), 41.

${ }^{25}$ Ibid., 42.

${ }^{26}$ P.-H. KOLVENBACH (2000), 157.

${ }^{27}$ P.-H. KolvenBACH (2006), 243.
} 
intelectual, la responsabilidad de una universidad de inspiración cristiana consiste en desarrollar un carácter más interdisciplinar, humanista y ético para poder cumplir con su misión, situándose en aquella vocación que es propiamente la suya, es decir, la búsqueda de la verdad en su totalidad y del conocimiento en su integridad humana" ${ }^{28}$

Desde esta perspectiva, nuestros planes de estudio no deben aceptar una súperespecialización que elimine contenidos esenciales para el desarrollo integral de la persona. A los responsables de esos planes les tocará decidir cuáles serán esos contenidos y de qué forma se incorporarán al currículo. Con todo, no deberían obviarse los contenidos de tipo histórico, epistemológico, social y ético. Son precisamente este tipo de contenidos los que pueden ayudar a situar las disciplinas que estudian nuestros alumnos en el lugar que les corresponde, evitando de esta manera positivismos trasnochados o irresponsabilidades a la hora de actuar en el mundo. Más aún, estos contenidos permitirán comprender a nuestros alumnos el carácter dinámico y social del conocimiento.

Desde el punto de vista ético, se hace del todo necesaria la formación interdisciplinar a la hora de presentar la no-neutralidad axiológica de las acciones humanas vinculadas, en especial, a la economía, la ciencia y la técnica; en otras palabras: la economía, la ciencia y la técnica no son neutrales en el terreno de los valores, pues los tienen, y bien precisos. Esta formación interdisciplinar es igualmente necesaria a la hora de analizar las antropologías que subyacen en todas las teorías económicas y sociales.

Dado el innegable poder de la ciencia y de la técnica, y dado que suele abundar la idea común que sitúa a la ciencia y a la técnica más allá de todo juicio moral, es imprescindible enseñar a los alumnos que la ciencia no debe entenderse únicamente como un conjunto de teorías; ni la técnica sólo como un conjunto de artefactos porque:

- Ciencia y técnica son sistemas que incluyen los agentes que deliberadamente buscan ciertas finalidades, en función de determinados intereses, para lo cual ponen en juego creencias, conocimientos, valores y normas.

- Los intereses, los valores, los fines forman parte de estos sistemas y son susceptibles de evaluación moral. ${ }^{29}$

\footnotetext{
${ }^{28} \mathrm{Ibid}$.

${ }^{29}$ Cfr. L. Olivé (2000), 86-87.
} 
La ciencia moderna se caracteriza por un ideal de operatividad y de dominio sobre la naturaleza, que se ha hecho realidad gracias a la "matematización" y a la experimentación. Este marcado carácter operativo y experimental no hace más que señalarnos las intrincadas relaciones que se dan entre la ciencia y la técnica actuales. Ambas se entrelazan hasta tal punto que ya son muchos los pensadores que utilizan un solo vocablo para referirse a las dos, "tecnociencia". Así pues, no sólo las acciones técnicas tienen consecuencias sobre el mundo, sino que la propia ciencia, por el mero hecho de experimentar, también actúa sobre la naturaleza. Diferentes poderes, como el político, el militar o el económico, se han dado cuenta del enorme potencial operativo de la ciencia, y por ello invierten importantísimos recursos para que se desarrolle $y$, de esta manera, esperan obtener ventaja de sus logros. Estos poderes condicionan enormemente las líneas de investigación científica al orientarlas con frecuencia hacia el desarrollo exclusivo de tecnologías que favorezcan sus intereses. Por ello, el pensador francés Jacques Ellul afirmaba que la ciencia se había convertido en un medio para la técnica. ${ }^{30}$ Se hace, pues, patente la carga axiológica de cualquier acción científica y de cualquier acción técnica. Ante este panorama, se hace del todo imprescindible que nuestros alumnos aprendan a descubrir los dilemas éticos que plantean las acciones tecnocientíficas.

Tal como señala el filósofo Evandro Agazzi, ${ }^{31}$ si la ciencia entendida como "saber" debería ser neutra, y los que la hacen posible deberían trabajar para que así sea, la ciencia entendida como "actividad" no es neutra ni puede serlo, por lo que tiene que ser objeto de análisis y de juicio ético.

Surge aquí una nueva pregunta: ¿̇Hacia dónde deberían apuntar nuestras líneas de investigación?

Al mencionar a Jacques Ellul, hemos aludido al dominio de la técnica sobre la ciencia. De hecho, son muchos los pensadores que sostienen, como Ellul, que la tecnología actual juega un papel determinante, no sólo sobre la ciencia, sino también sobre el hombre y sobre la sociedad, como, por ejemplo, Martin Heidegger ${ }^{32}$ y José Ortega y Gasset. ${ }^{33}$ Para Ellul, el hombre actual vive en un medio técnico en

\footnotetext{
${ }^{30}$ Cfr. J. ELuU (2003).

${ }^{31}$ Cfr. E. Agazzl (1996).

32 Cfr. M. Heidegger (2001).

33 J. ORtega y Gasset (1992).
} 
el que la tecnología conforma un sistema que abarca cada vez más ámbitos de la vida humana. En el medio técnico, los medios se convierten en fines, y por ello al hombre se le hace difícil encontrar sentido. ${ }^{34}$

En esta misma línea se expresa Ortega y Gasset cuando afirma la enorme dificultad que tiene el hombre actual para dar sentido a su vida. Para el pensador madrileño,

los deseos referentes a cosas se mueven siempre dentro del perfil del hombre que deseamos ser. Este es, por lo tanto, el deseo radical, fuente de todos los demás. Y cuando alguien es incapaz de desearse a sí mismo porque no tiene claro un sí mismo que realizar, no tiene sino pseudo-deseos, espectros de apetitos sin sinceridad ni vigor. (...) El hombre actual no sabe qué ser, le falta imaginación para inventar el argumento de su propia vida. ${ }^{35}$

Se hace necesario dotar a nuestros alumnos de aquellos elementos que les permitan, más allá del puro pensamiento estratégico, formular, analizar y criticar los fines de sus acciones, en definitiva buscar y dar sentido a sus vidas más allá de las constricciones que les impone el sistema técnico en el que nos hallamos inmersos.

La responsabilidad de llevar a cabo la tarea de formar interdisciplinarmente no ha de recaer exclusivamente en los profesores de asignaturas dedicadas a la ética o a la responsabilidad social. Si bien han de existir asignaturas de ética aplicada para cada una de las profesiones correspondientes a los grados que impartimos, es importante que la interdisciplinariedad se halle presente, en la medida de lo posible, de forma transversal en el mayor número de asignaturas posible. Tomemos la ética como ejemplo: es importante que el profesor de otra asignatura, cualquiera que no sea Ética, haga comentarios o plantee cuestiones éticas acerca del terreno práctico estudiado en su asignatura. Muchos profesores se sienten aquí inseguros al no haber sido preparados para esto; por ello, sería positivo formar a los profesores en todos aquellos contenidos que les faciliten la reflexión interdisciplinar. En este sentido, actividades tales como seminarios entre profesores de diferentes disciplinas, ciclos de conferencias o simposios que planteen cuestiones interdisciplinares pueden resultar de gran utilidad. No debemos olvidar que

\footnotetext{
${ }^{34}$ Obviamente, en esta frase hemos utilizado la palabra "medio" en dos sentidos distintos: "medio técnico" en el sentido de "entorno", "matriz", en francés, "milieu", y "medios" en el sentido de "instrumentos", en francés, "des moyens".

35 J. Ortega y Gasset (1992), 55-56.
} 
la educación jesuita aspiraba, y aspira, a la formación de personas más plenamente humanas, y que este credo y tradición humanísticos deberían producir un impacto en todos los aspectos y en todas las materias de la empresa educativa jesuítica. ${ }^{36}$

La naturaleza también deberá formar parte de nuestra consideración y formación. La filosofía griega no la había considerado como responsabilidad del hombre, y tanto la economía de mercado como la economía colectivista tampoco la habían tenido presente hasta hace poco tiempo. Sin embargo, los efectos del impacto del desarrollo tecnológico sobre el medio ambiente, principalmente a partir de la Revolución Industrial, han hecho que el hombre tenga que plantearse su relación con el medio natural. No cabe ninguna duda de que el hombre ha tenido que aceptar, desgraciadamente desde hace relativamente poco tiempo, su papel de cuidador de la naturaleza y asumir su responsabilidad sobre ésta. En particular, la ciencia, la ingeniería y la economía ya no pueden obviar la naturaleza y deben hacerse cargo de los retos medioambientales que el hombre tiene planteados al respecto.

La interdisciplinariedad, en contraposición a la súper-especialización, y la inclusión de la naturaleza, frente a su clásico olvido, son dos elementos ya imprescindibles en una formación integral de la persona. En palabras de Kolvenbach, esta visión holística, esto es, la búsqueda de la verdad en su totalidad y del conocimiento en su integridad humana, "hará a los profesores y a los estudiantes más humanos, por cuanto captarán mejor el sentido de lo que enseñan y de lo que estudian, promoviendo un desarrollo humano, social y ecológicamente equilibrado" ${ }^{37}$

\section{Un humanismo que promueve la libertad y la justicia}

Para Kolvenbach, el significado de la educación humanística es el siguiente:

Una sensibilidad dirigida hacia la miseria y explotación de los hombres no es simplemente una doctrina política o un sistema económico. Es un humanismo, una sensibilidad humana que debe lograrse de nuevo dentro de las dimensiones de nuestro tiempo y como resultado de una educación cuyo ideal está influido por los grandes mandamientos: amar a Dios y al próiimo. ${ }^{38}$

\footnotetext{
36 P.-H. KOLVENBACH (2007), 261.

${ }^{37}$ P.-H. KOLVENBACH (2006), 243.

${ }^{38}$ P.-H. KOLVENBACH (1993), 127.
} 
La educación humanística de la que nos habla Kolvenbach no se detiene en la descripción y análisis de la realidad que, a veces, se nos presenta plagada de injusticias. Debe haber propuestas concretas porque la educación humanística jesuítica ha consistido en una lucha por la dignidad humana y los derechos humanos, la libertad ilustrada de la conciencia, y la libertad responsable de la palabra, el diálogo respetuoso y una paciente promoción de la justicia. ${ }^{39}$

Para que nuestros centros sean promotores de la libertad y de la justicia es necesario desarrollar una doble vía: 1/ del exterior al interior de la universidad, lo cual permite incorporar en los contenidos de nuestras asignaturas datos que describen las realidades del Tercer y del Cuarto Mundo para que puedan ser analizados, intentando mostrar las causas de la desigualdad y de la pobreza que se dan en estas realidades; y 2/ del interior al exterior de la universidad, con una doble función, académica y social. Mediante la función académica se denuncian la desigualdady la pobreza, se investiga acerca de ellas y se proponen soluciones para combatirlas. Y mediante la función social se facilita el contacto de alumnos y profesores con estas realidades a través del voluntariado social o de asignaturas de cooperación social; también cabe proponer aquí la cooperación entre diferentes universidades de la Compañía de Jesús para contribuir a la formación de profesores de países cultural y económicamente desfavorecidos, así como impulsar el intercambio de alumnos de diferentes países, aunque este intercambio resulte en muchos casos numéricamente asimétrico, dado que suele haber más demandas para viajar de sur a norte que de norte a sur, por decirlo de una manera simple pero clara. Las tecnologías de la información y de la comunicación ofrecen nuevas oportunidades de cooperación que deberán ser exploradas.

De hecho,

el magis no se refiere sólo a lo académico, sino también a la acción. Nuestra formación incluye experiencias que nos hacen explorar las dimensiones y manifestaciones del servicio cristiano como medio para desarrollar nuestro espíritu de generosidad. ${ }^{40}$

Otro reto es conseguir que la educación humanística promueva en nuestros alumnos el interés activo por hallar soluciones a problemas sociales y económicos que se dan en el planeta. ¿2Preparamos a nuestros alumnos para reforzar la cohesión social y para fomentar un sentimiento de conciencia y de responsabilidad cívica?

\footnotetext{
39 P.-H. KOLVENBACH (2007), 261.

40 P.-H. KOlvenBACH (1993), 132.
} 
Ante los problemas globales que ultrapasan los Estados-nación, debemos trabajar para reconstruir el espacio público, cada vez más abandonado, o simplemente inexistente, aquel espacio en el que hombres y mujeres puedan establecer un diálogo continuo entre el ámbito de lo personal y el ámbito de lo colectivo.

\section{Conclusiones}

El análisis y la revisión de la actividad docente e investigadora de los centros superiores de la Compañía de Jesús a la luz del "paradigma Ledesma-Kolvenbach", en particular de la dimensión "humanitas", pueden resultar muy positivos principalmente en lo que a la identidad y misión se refiere, más aún teniendo en cuenta que nos encontramos en un proceso de cambio universitario como es el propiciado por el Espacio Europeo de Educación Superior (EEES) - Bolonia.

En la "humanitas" propuesta por Kolvenbach, los alumnos deben ser una referencia central del proyecto universitario de los jesuitas, en especial, en la docencia y en las relaciones humanas. Este proyecto ha de promover la cooperación y el trabajo en equipo de los estudiantes evitando una competitividad malsana, y ha de revisar los conceptos de "éxito" y de "fracaso", procurando que no se confunda "éxito" con la simple "excelencia académica o profesional". No cabe duda de que la atención a aquellos alumnos que cursan bien sus estudios en nuestras aulas es fundamental, pero no es menos importante el seguimiento de los alumnos con problemas, para poder orientarlos a encontrar su camino. Todo ello debería ir enmarcado en el principio ignaciano del "magis", por el cual cada hombre tiene una responsabilidad en relación a los talentos que ha recibido (Mt 25,14-30).

Situados en la sociedad de la información, es vital dotar a los alumnos de las competencias necesarias para que puedan ser críticos ante la avalancha de informaciones a las que están sometidos, y capaces de elaborar un conocimiento riguroso.

Frente al marco individualista que tanto abunda en la actualidad, se hace necesario crear espacios propicios para el encuentro con el otro. Este encuentro resulta esencial para la convivencia en una sociedad plural, en la que el diálogo y la tolerancia activa deberían ser un pilar importante.

Dado el peso de la ciencia y de la técnica en nuestra sociedad, no pueden obviarse los análisis de las antropologías subyacentes a las teorías sociales, ni tampoco la responsabilidad ética que siempre plantea cualquier acción científica o técnica. 
La responsabilidad ética ha de incluir tanto la preocupación por lo humano como por lo medioambiental. En ese sentido, debemos revisar hacia dónde apuntan nuestras investigaciones y proyectos tecnocientíficos. La formación interdisciplinar de alumnos y profesores resulta clave para estas cuestiones.

Esta formación interdisciplinar permite ir más allá de la hiperespecialización en el campo del conocimiento para entrar en un tipo de saber holístico, que permite interpretar mejor la realidad y ayuda a elaborar discursos de sentido.

Finalmente, la dimensión "humanitas" anima a promover en nuestros centros la toma de conciencia de la injusticia social -local y global-, que incluye tanto su conocimiento como la puesta en práctica de acciones para acabar con ella, como puede ser la promoción del voluntariado en toda la comunidad educativa y la colaboración con otras universidades nacionales y extranjeras.

\section{Bibliografía}

AgAzZI, E. (1996), El bien, el mal y la ciencia. La dimensiones éticas de la empresa científico-tecnológica, Madrid, Tecnos.

BAUMAN, Z. (2007), Els reptes de l'educació en la modernitat líquida, Barcelona, Arcàdia.

CG35 - Congregación General 35 de la Compañía de Jesús, Roma, del 7 de enero al 6 de marzo de 2008. Edición castellana a cargo de Ernesto Cavassa y Elías Royón, Bilbao y Mailaño, Mensajero y Sal Terrae, 2008.

CoRTINA, A. (1994), Ética de la empresa, Madrid, Trotta.

DuvAl, A. (1997), El niño que jugaba con la luna, Santander, Sal Terrae.

ELuL, J. (2003), La edad de la técnica, Barcelona, Octaedro.

Gomis, C. (2006), "Emmanuel Lévinas, pensar el bien", El Ciervo 666-667 (septiembre-octubre), Barcelona.

GonzÁlez Faus, J.I. (1987), Proyecto de hermano, Santander, Sal Terrae.

González-Carvajal, L. (1998): Entre la utopía y la realidad, Santander, Sal Terrae. 
Heidegger, M. (2001), "La pregunta por la técnica", en: HeidegGer, M., Conferencias y artículos, Barcelona, Ed. del Serbal.

Judson, H. F. (2006), Anatomía del fraude científico, Barcelona, Crítica.

KolvenBACH, P.-H. (1993), "La pedagogía ignaciana hoy", Conferencia a los participantes del grupo de trabajo sobre "La Pedagogía Ignaciana: Un planteamiento práctico" (Villa Cavalletti, Roma, 29 de abril), en: KolveNBACH, P.-H. (2008), Discursos Universitarios, selección e introducción del P. Melecio Agúndez, UNIJES, 124-139.

KolvenBACH, P.-H. (2000), "Alocución en la Universidad de Saint-Joseph" (Beirut, 19 de marzo de 2000), en: KolvenBaCH, P.-H. (2008), op. cit., 154-168

KolveNBACH, P.-H. (2006), "Evolución del encuentro entre ciencia y fe" (conferencia pronunciada en la Clausura del Centenario del Instituto Químico de Sarriá [IQS], en Barcelona, el 14 de julio de 2006), en: KolvenBACH, P.-H. (2008), op. cit., 236-248

KolvenBaCH, P.-H. (2007), "Al Consejo Directivo de la Universidad de Georgetown" (conferencia pronunciada en la Universidad Gregoriana, Roma, el 10 de mayo de 2007), en: KolveNBACH, P.-H. (2008), op. cit., 256-268

Ouvé, L. (2000), El bien, el mal y la razón, Barcelona, Paidós.

Ortega y Gasset, J. (1992), Meditación sobre la técnica y otros ensayos sobre ciencia y filosofía, Madrid, Revista de Occidente en Alianza Editorial. 